\title{
Naked Short Selling and Market Returns ${ }^{\text {is }}$
}

\author{
Thomas J. Boulton ${ }^{*}$ \\ Farmer School of Business, Miami University, Oxford, OH 45056, USA \\ Marcus V. Braga-Alves \\ College of Business Administration, Marquette University, Milwaukee, WI 53201, USA
}

Initial Draft: March, 2009

Current Draft: July, 2009

Running Head: Naked short selling and market returns

JEL classification: D02; G14; G28

Keywords: Failures to deliver; naked short selling; stock returns

it The authors thank Brandon Carl, Terry Nixon, Sarah Peck, Steve Wyatt, and Chad Zutter for valuable comments. Any remaining errors or omissions remain the responsibility of the authors.

* Corresponding author. Tel.: + 1-513-529-1563; fax: + 1-513-529-8598.

E-mail address: boultotj@muohio.edu (T. Boulton). 


\title{
Naked Short Selling and Market Returns
}

\author{
Abstract \\ We examine stock market returns around periods of increased naked short selling with two \\ objectives in mind. First, we study persistent failures to deliver (FTDs) for insight into naked \\ short sellers' trading strategies and their ability to identify overpriced stocks. We find that naked \\ short sellers are contrarians who target stocks that experience positive abnormal returns. Returns \\ following transactions that result in persistent FTDs provide no evidence that naked short sellers \\ are informed traders. Second, we study the market's reaction to announcements indicating \\ increased levels of naked short selling. We find that abnormal returns are generally positive \\ following such announcements.
}

JEL classification: D02; G14; G28

Keywords: Failures to deliver; naked short selling; stock returns 


\section{Naked Short Selling and Market Returns}

\section{Introduction}

Critics describe naked short selling (i.e., selling a stock short without first borrowing or arranging to borrow it) as abusive and manipulative, suggesting that naked short selling has negative consequences for the security being sold short. Consistent with this notion, the U.S. Securities and Exchange Commission (SEC) has targeted naked short selling in recent regulatory actions described as "in the public interest and for the protection of investors to maintain fair and orderly securities markets, and to prevent substantial disruption in the securities markets."1 Despite the recent criticism of naked short sellers, little is known about their trading strategies and the market's perception of naked short selling. For example, although some speculate that naked short sellers are momentum traders who exacerbate price declines, we are aware of no rigorous empirical evidence to support such a claim. We study market returns around periods of increased naked short selling to examine the trading strategies of naked short sellers and the market's reaction to information about their trades.

Although studies of naked short selling are relatively uncommon, recent regulatory actions designed to curtail the practice have generated interest from researchers. For example, Boulton and Braga-Alves (2009) study the SEC's 2008 Emergency Order restricting naked short selling of 19 financial firms' stocks and find evidence consistent with Miller's (1977) conjecture that short sale constraints can negatively impact market efficiency by inflating prices, leading to low subsequent returns. They also find that the restrictions damaged liquidity in the stocks they

\footnotetext{
${ }^{1}$ Securities and Exchange Commission, Release No. 34-58572/ September 17, 2008, p. 3.
} 
were designed to protect, reflected in higher trading costs and lower trading volume. In a related study, Fotak et al. (2009) find that naked short selling has a positive effect on market quality and, consistent with Boulton and Braga-Alves, report evidence that the SEC's 2008 Emergency Order had a negative effect on the price discovery process and liquidity. The authors conclude that their results stand in contrast to the negative perception of naked short selling.

One reason for the lack of research in this area is that market participants are not required to identify naked short sales, which makes them difficult to study. We proxy for naked short sale activity using failures to deliver (FTDs), which occur when a seller does not deliver securities to the buyer within the standard three-day settlement period. Beginning with Regulation SHO in 2005, each U.S. exchange is required to disseminate a daily list of securities that reach threshold levels of aggregate, open FTDs equal to, or greater than, 10,000 shares and $0.5 \%$ of the total shares outstanding for 5 consecutive settlement days. Although FTDs occur for reasons other than naked short selling, including processing errors and delays in delivering securities held in certificate form, we argue that persistent FTDs that lead to threshold listings are highly correlated with naked short selling.

We use persistent FTDs to examine stock market returns around periods of increased naked short selling with two objectives in mind. First, we conduct an event study around threshold listings to examine naked short sellers' trading strategies and their ability to identify overpriced stocks. Regulators have justified recent naked short sale restrictions by suggesting that naked short sellers are momentum traders who intensify downward price movements. If naked short sellers are momentum traders, we should expect them to target stocks that have recently experienced negative returns. We find the opposite to be true. Consistent with Angel et al. (2003) and Diether et al. (2008), we find that naked short sellers are contrarian investors who 
tend to target stocks following positive abnormal returns. Depending on the criteria used to define an event, cumulative abnormal returns (CARs) are $1.7-5.7 \%$ over the 2 trading days ending with the date of the naked short sale transaction(s) that leads to a security appearing on a threshold list (i.e., the threshold trades).

Our examination of the trading strategies of naked short sellers also includes tests of Diamond and Verrecchia's (1987) information-based explanation for elevated short selling, which predicts that short sellers are informed traders who can forecast negative returns. Contrary to studies of short selling that find support for Diamond and Verrecchia's prediction (e.g. Arnold et al., 2005; Asquith and Meulbroek, 1996; Asquith et al., 2005; Boehmer et al., 2008; and Desai et al., 2002), we do not find that persistent FTDs indicate that stocks are overpriced. Instead, we find that stocks that experience persistent FTDs exhibit positive CARs in the period immediately following the threshold trades. For example, CARs average $1.3-1.6 \%$ over the 7 trading days between the threshold trades and the threshold list appearance. While contrary to the notion that persistent FTDs predict negative returns, this result is consistent with naked short sellers deliberately failing to deliver shares in to the face of rising share prices.

Second, we examine the stock market's reaction to announcements that firms have been added to the threshold lists, which is indicative of increased naked short selling. Theory suggests that market participants could view increased naked short selling as positive information, negative information, or uninformative. Desai et al. (2002) point to a popular notion on Wall Street that high levels of short interest is a bullish signal since short positions represent latent demand as shorts eventually must cover their positions. However, Diamond and Verrecchia's (1987) theory suggests that the costs associated with short selling increase the likelihood that short sellers are informed traders, implying that information indicating increased naked short 
selling is a negative signal. Consistent with this conjecture, Aitken et al. (1998) study the Australian Stock Exchange where short sale information is available in real time and find that short sales are followed by nearly instantaneous negative abnormal returns. The third possibility is that information on naked short selling does not impact stock prices. This could be the case if, for example, naked short selling is driven by hedging concerns, arbitrage trading, and tax strategies (see Senchack and Starks, 1993). Consistent with the notion that increased naked short is a positive signal to market participants, we report average CARs of $1.3-1.9 \%$ over the 5 trading days following the announcement that a security has reached threshold levels of FTDs (i.e., a threshold event).

Our analysis contributes to the extant literature in several important ways. First, we are the first to specifically examine the trading strategies of naked short sellers. There is a wealth of information on the activities of short sellers, in general, that fails to distinguish covered short sales from naked short sales. Because a naked short seller does not have a binding lending agreement at a specific price in place at the time of the short sale, naked short selling is inherently more risky than covered short selling. This may lead to pronounced differences in the strategies of naked and covered short sellers. Second, this study advances our understanding of FTDs. Recent studies of FTDs include Boni (2006), who finds that the probability of FTDs is a function of a stock's short interest levels, and Evans et al. (2009), who find that failures outweigh deliveries when rebate rates are zero. Both studies suggest that FTDs are related to hard-to-borrow stocks. We are the first to document stock market returns around transactions that result in threshold levels of FTDs and public announcements that firms have reached threshold levels of FTDs. Third, our results support recent studies that suggest that the SEC's efforts to stem the recent financial crisis by preventing naked short selling may have been misguided, as 
we do not find that naked short sellers target stocks experiencing price weakness or that announcements indicating increased naked short selling have a negative impact on stock prices. Instead, our results are consistent with the consensus in academic research that short sales contribute positively to well-function markets.

The remainder of this paper is structured as follows. Section 2 details FTDs, naked short sales, and the threshold lists while formally developing our hypotheses. Section 3 describes our sample and methodology. Section 4 reports our results on the empirical relation between naked short selling and stock prices. Section 5 summarizes and concludes.

\section{Failures to deliver and hypotheses development}

A failure to deliver occurs when a seller does not deliver securities to the buyer within the standard three-day settlement period. FTDs occur for a number of reasons, including processing errors, delays in delivering securities held in certificate form, and naked short selling. In a naked short sale transaction, a fail results if the seller does not obtain the shares necessary to make delivery within the three-day settlement period. Securities with an aggregate level of open FTDs equal to, or greater than, 10,000 shares and $0.5 \%$ of the total shares outstanding for 5 consecutive settlement days appear on their exchange's daily threshold list. A security remains on the threshold list until the aggregate level of open FTDs drops below the threshold criteria for 5 
consecutive trading days. Broker-dealers are required to close-out open fail positions that persist for 13 consecutive trading days during which a security appears on a threshold list. ${ }^{2}$

Although FTDs can originate for reasons other than naked short sales, several factors suggest that threshold listings are highly correlated with an increase in speculative positions established to profit from positive pricing errors. The requirements for appearing on a threshold list-aggregate, open FTDs equal to, or greater than, 10,000 shares and $0.5 \%$ of the total shares outstanding for 5 consecutive settlement days-make it unlikely that processing errors and inadvertent delivery delays are the genesis of many threshold listings. We expect that the rare instances where processing errors and delivery delays do contribute to threshold listings are random and do not systematically bias our results. Likewise, the threshold lists are unlikely to reflect naked short positions established by market makers due to a temporary order imbalance and day traders hoping to capitalize on intra-day price declines, both of which would be expected to cover their positions before FTDs meet the threshold criteria. Given that firms appear on the threshold lists only following persistent failures of a meaningful fraction of total outstanding shares, we believe that FTDs proxy for stocks targeted by naked short sellers who have established positions with the expectation of profiting from inter-day price declines. This conjecture is supported by Fotak et al. (2009) who report that the number of new FTDs is highly correlated with trading volume arising from short sales but not correlated with trading volume arising from transactions other than short sales.

\footnotetext{
2 On July 27, 2009, the SEC made permanent Rule 204T of Regulation SHO. Rule 204T, which was temporarily approved in fall of 2008, requires broker-dealers to close-out FTD positions resulting from a short sale by the beginning of the trading day immediately following the day on which the fail occurs.
} 
In Figure 1, we provide a timeline that details the sequence of events leading to a failure to deliver, threshold status, and a security's removal from the threshold lists. Considering a firm's appearance on a threshold list as the benchmark day (day t), the naked short sale transaction(s) that pushes a firm above the threshold level of FTDs (i.e., the threshold trades) occurs on day t-7. Insight into the trading strategies of naked short sellers can be gleaned from the performance of the stocks that they target in the days leading up to day $\mathrm{t}-7$. If naked short sellers are momentum traders who contribute to price declines we should expect negative returns for the stocks that they target in the period leading up to the threshold trades. Alternatively, if naked short sellers are contrarian investors who take positions in stocks they view as overpriced, we should expect positive returns for the stocks that they target in the period immediately prior to the threshold trades. This leads us to our first testable hypothesis:

\section{H1. Naked short sellers are momentum (contrarian) investors who target stocks following} negative (positive) returns.

We test the preceding hypothesis by examining CARs over the $[-12,-7]$ and $[-8,-7]$ windows, where day $\mathrm{t}-7$ is the day of the threshold trades.

\section{<<FIGURE 1 ABOUT HERE>>}

Trades that take place on day $\mathrm{t}-7$ are expected to settle on day $\mathrm{t}-4$, otherwise a fail occurs. Securities that meet or exceed threshold levels of FTDs for 5 consecutive trading days appear on the threshold lists. If fails that initially occur on day $\mathrm{t}-4$ result in a security reaching threshold 
levels of FTDs that persist for 5 consecutive trading days, the security appears on a threshold list on day t. This implies that naked short positions can remain open for 8 days before the market is alerted through the dissemination of the threshold lists. If, as Diamond and Verrecchia (1987) suggest, naked short sellers possess superior information that allows them to profit from subsequent price declines, we should observe negative returns in the period immediately following the threshold trades. This leads us to our second hypothesis:

H2. Naked short sellers are informed traders who profit from short positions they establish prior to price declines.

We test our second hypothesis by examining CARs over the $[-6,0]$ and $[-6,+13]$ windows, where day t-6 is the day after the threshold trades.

The market's reaction to information about the activity of naked short sellers can be observed by examining CARs after the release of the threshold lists. If, as Diamond and Verrecchia (1987) suggest, naked short sellers are informed traders whose activities convey negative information, we should observe negative returns in the period immediately following the announcement of a stock's addition to the threshold lists. If latent demand makes increased naked short selling a bullish signal, returns should be positive following the announcement of threshold list additions. Finally if naked short selling is driven by hedging concerns, arbitrage trading, and tax strategies, the market reaction to threshold announcements should be neutral. Our third testable hypothesis is as follows: 
H3. The market views new threshold listings as negative (positive) information which is reflected in negative (positive) returns in the period following the release of the threshold lists.

The threshold lists for day $t$ are released after the markets close, preventing investors from trading on the information contained in the lists until day $t+1$. We test the preceding hypothesis be examining CARs over the $[+1,+5]$ window.

Securities are removed from the threshold lists when the aggregate level of open FTDs drops below threshold levels for 5 consecutive trading days. Therefore, day $t+5$ is the first day that a security can be removed from the threshold lists. Broker-dealers are required to close-out fail positions that persist for 13 consecutive trading days during which a security is on the threshold lists.

In Figure 2, we report the daily number of securities appearing on the AMEX, Nasdaq, and NYSE threshold lists from 2005 through 2008. The average daily number of threshold securities reported by the AMEX, Nasdaq, and NYSE are 60, 228, and 66, respectively. The broad trend over the sample period was a gradual increase in the number of threshold securities until the third quarter of 2008. A temporary pause in the upward trend occurred in August 2007, when the SEC announced the elimination of a "grandfather" exception that exempted failure to deliver positions established before a security reached threshold levels from the mandatory closeout requirement. On September 17, 2008 the SEC issued an Emergency Order prohibiting naked short sales for all securities under their jurisdiction. ${ }^{3}$ This regulation resulted in a sudden and

${ }^{3}$ Securities and Exchange Commission, Release No. 34-58572/ September 17, 2008. 
significant decline in the number of securities on the threshold lists during the final months of our sample period. The abrupt decline in the number of securities on the threshold lists following the SEC's Emergency Order prohibiting naked short sales supports our argument that FTDs are highly correlated with naked short selling.

\section{$<$ FIGURE 2 ABOUT HERE >>}

In Figure 3, we report a frequency distribution of the total number of threshold events for firms that appear on the threshold lists at least once. In this figure, a threshold event is defined as an appearance on the threshold lists after an absence of at least 5 days. The average threshold security appears on the threshold lists 2.75 times between 2005 and 2008 . Over $40 \%$ of the securities make only one appearance on the threshold lists and $74 \%$ of the securities make 3 or fewer total appearances during our sample period. At the other end of the spectrum, NVE Corporation makes 19 unique appearances on the threshold lists.

\section{<<FIGURE 3 ABOUT HERE〉>}

While the typical stay on the threshold lists is about 17 days, some firms remain for an extended period. In Figure 4, we illustrate how long firms remain on the threshold lists once they appear. Over $68 \%$ of threshold events last for 15 or fewer days, with a median of 11 days. Extended stays are less common, with about $11 \%$ of threshold events lasting longer than 30 days. Medis Technologies, which ended a run of 759 consecutive trading days on the Nasdaq's threshold list on August 13, 2008, is the sample stock with the longest streak on the threshold 
lists. The most common duration is 5 days, which corresponds to the minimum duration based on the SEC's criteria for being removed from the threshold lists. However, we do find a small number of firms with stays that last 4 or fewer days. ${ }^{4}$

\section{<<FIGURE 4 ABOUT HERE >>}

\section{Sample and methodology}

\subsection{Sample selection and event identification}

We use the threshold lists provided by the AMEX, Nasdaq, and NYSE to identify our sample events. ${ }^{5}$ Firms move on and off the threshold lists with great regularity. To capture events that are informative to market participants, we calculate the time between appearances on the threshold lists and define events as (a) a firm's first appearance on the threshold lists and (b) reappearances after a 30-, 90-, or 180-day absence. We use 2005 as the base year for identifying events, resulting in a sample that spans 2006 through 2008. Because we require CRSP data for

\footnotetext{
${ }^{4}$ The total number of listings lasting less than 5 days is less than 2 percent of our sample. Unreported tests confirm that our results are robust to excluding these events.

${ }^{5}$ Threshold lists are available through the following websites: Amex (http://www.amex.com/amextrader/tradingData/RegSHO/TrDa_RegSHO.jsp), Nasdaq (ftp://ftp.nasdaqtrader.com/symboldirectory/regsho), and NYSE (http://www.nyse.com/regulation/nyse/Threshold_Securities.shtml).
} 
our event study, we exclude events that do not correspond to ordinary common stocks covered by CRSP. Finally, we exclude penny stocks to alleviate concerns about the bid-ask bounce. ${ }^{6}$

In Table 1, we report summary statistics for our event sample. The first column reports results for securities appearing on the threshold lists for the first time. This definition results in 955 unique threshold events. The average firm's market capitalization as measured on day t- 8 is over $\$ 627$ million. The typical stock has a price slightly below $\$ 16 /$ share. The average standard deviation of returns is $3.7 \%$ and the average daily trading volume is $1.5 \%$ of shares outstanding as measured over the 22 trading days ending with day t-9. We find that $10.5 \%$ of first time threshold firms operate in one of the high tech industries identified by Ljungqvist and Wilhelm (2003), 65.1\% are listed on the Nasdaq, and 34.3\% appear on the threshold lists for the first time during calendar year 2008. We report similar information for our 30-, 90-, and 180-day samples.

\section{<<TABLE 1 ABOUT HERE >>}

\subsection{Methodology}

We follow Christophe et al. (2007) and report abnormal returns in all our tests. We measure abnormal returns using the market model as our benchmark (Brown and Warner, 1985). The model is

\footnotetext{
${ }^{6}$ Unreported tests indicate that the results are robust to alternative definitions of a sustained absence from the threshold lists and to higher minimum share prices.
} 


$$
R_{j t}=\alpha+\beta_{j} R_{m t}+\varepsilon_{j t}
$$

where $R_{j t}$ is the return on the $j^{\text {th }}$ stock on day $t$ and $R_{m t}$ is the return on the market index on day $t$. $\beta_{j}$ measures a stock's sensitivity to the market risk factor.

Daily abnormal returns are measured for common stock $j$ on day $t$ as

$$
A R_{j t}=R_{j t}-\left(\hat{\alpha}_{j}+\hat{\beta}_{j} R_{m t}\right)
$$

where $\hat{\alpha}_{j}$ and $\hat{\beta}_{j}$ are the ordinary least squares estimates from equation (1). We estimate equation (1) over the 255 trading days ending at least 46 days before the event and calculate abnormal returns for each stock with equation (2). We use the CRSP equally weighted portfolio to proxy for the market index.

\section{Empirical results}

The focus of our event study analysis is twofold. First, we study naked short sellers' behavior for insight into their trading strategies and their ability to identify overpriced stocks. We find that naked short sellers are contrarians who trade following positive abnormal returns. Our examination of persistent FTDs provides no evidence that naked short sellers are informed traders who profit from subsequent negative abnormal returns. Second, we study the market's reaction to announcements indicating increased levels of naked short selling. We find abnormal returns are generally positive following such announcements.

\subsection{Threshold event abnormal returns}


In Table 2, we report abnormal returns around threshold events. In Panel A, we report daily abnormal returns over the $[-12,+13]$ window where day zero is the day a stock appears on an exchange's threshold list. Our window begins 5 trading days before the threshold trades, which allows us to study the stock market performance of the firms targeted by naked short sellers, and ends with the mandatory close-out date, which enables us to examine stock market performance subsequent to the threshold trades and around the announcement that a stock has been added to the threshold lists. We report results for four threshold event definitions. In the first column of results, threshold events are the first-time a security appears on the threshold lists. In subsequent columns we report the results for securities reappearing on the threshold lists after an absence of at least 30-, 90-, and 180-days, respectively.

\section{$<<$ TABLE 2 ABOUT HERE $>$}

In Table 2, Panel A, we find that mean daily abnormal returns tend to be positive and statistically significant around threshold events. Using first time threshold listings as the benchmark for discussion, we find that abnormal returns are significant around the day of the threshold trades (t-7) and the event day ( $\mathrm{t})$. A large positive abnormal return of $1.56 \%$ is observed on the day of the threshold trades (t-7). While not consistent with the notion that naked short sellers are momentum traders, this result is consistent with Angel et al. (2003) and Diether et al. (2008), who find evidence that short sellers are contrarian investors who target stocks that recently experienced positive returns.

Because the daily threshold lists are released after the close of trading on day t, the market cannot act on the new information contained in the lists until the following trading day. 
Perhaps our most interesting finding is that abnormal returns are positive and both statistically and economically significant for the two trading days following a threshold event. For example, we report that stocks appearing on the threshold lists for the first time experience average abnormal returns of $0.4 \%$ on day $t+1$ and $0.5 \%$ on day $t+2$. This is consistent with the notion that increased naked short selling is a bullish signal because it represents latent demand for the stock being shorted. The 30-, 90-, and 180-day samples lead to similar inferences.

In Table 2, Panel B, we report CARs over several windows around threshold events. Return windows ending on the day of the threshold trades ( $\mathrm{t}-7)$ continue to support the notion that naked short sellers are contrarian investors who target stocks that have recently experienced positive returns. Two-day CARs ending on the day of the threshold trades average $1.72-5.66 \%$ for first-time threshold listings. We report positive CARs over the $[-6,0]$ window, which corresponds to the period between the threshold trades and the day the firm appears on a threshold list. This indicates that naked short sellers are generally not able to profitably close out their short positions before a stock appears on the threshold lists and suggests that short sellers may choose not to deliver in the face of rising prices. On the other hand, it is contrary to the notion that naked short sellers are informed traders. CARs are positive over the five days following a security's appearance on the threshold lists, suggesting that market participants do not view the news that a security has reached threshold levels negatively. Finally, we report CARs of $2.79-4.31 \%$ over the $[-6,+13]$ period, which begins on the day after the threshold trades and ends on the mandatory close out day. This suggests that the stocks target by naked short sellers outperform the market over an extended period following the threshold trades, which is the opposite of what we should expect if naked short sellers possessed superior information that allowed them to profit from subsequent price declines. 
Our Table 2 results for naked short sellers complement Angel et al. (2003) and Diether et al. (2008) who find that short sellers tend to transact following positive returns. This is consistent with the notion that short sellers promote efficient markets by providing liquidity in up markets, risk-bearing, and selling stocks they view as overpriced and contrary to the claim that naked short sellers are momentum investors who exacerbate downward price momentum. Our results for naked short sellers are not consistent with studies, including Arnold et al. (2005), Asquith and Meulbroek (1996), Asquith et al. (2005), and Desai et al. (2002), that conclude that short sellers are informed. Instead, we find that threshold stocks outperform expectations following threshold trades and the public dissemination of threshold information. Also, consistent with naked short selling representing a bullish signal due to latent demand, we find that market participants tend to react positively when stocks appear on the threshold lists.

\subsection{Cumulative abnormal returns by year}

Naked short sellers have been blamed, at least in part, for the crisis that gripped financial markets in 2008. To explore the possibility that naked short sellers' trading strategies and the market's reaction to threshold events is not consistent across our sample period, we report CARs around threshold events on a year-by-year basis in Table 3. We find that the positive CARs reported for the full sample for the period before the threshold trades are larger in the earlier years of our sample. For first time threshold listings, the average CAR over the interval $[-8,-7]$ is $4.02 \%$ (1.99\%) for events taking place in 2006 (2007). This compares to a two-day CAR of $0.42 \%$ in 2008 , a year characterized by extreme volatility and severe stock price declines. This suggests that naked short sellers' contrarian tendencies diminished over our sample period. CARs measured over the longer $[-12,-7]$ event window also suggest that naked short sellers 
targeted stocks with worse performance in 2008 when compared to 2006 and 2007. We report similar results for stocks reappearing on the threshold lists after 30-, 90-, and 180-day absences. Although CARs are significantly larger in 2006 than in later years, there is no evidence to suggest that naked short sellers generally focused on underperforming stocks in any of the sample years as CARs for periods ending on the day of the threshold trades are unanimously positive for stocks reappearing on the threshold lists.

\section{<<TABLE 3 ABOUT HERE>>}

The positive CARs reported for the period $[-6,0]$ continue to contradict the notion that naked short sellers are informed traders. We find that CARs over this interval are positive for all four event classifications in each sample year. This includes 2008, a year characterized by declining stock prices. This confirms earlier evidence that suggests that naked short sellers are not typically able to profitably unwind their positions before a stock appears on the threshold lists and is consistent with the conjecture that naked short sellers are more prone to strategically fail following price increases.

We report that CARs following threshold appearances are generally largest in 2008. For example, using the first time threshold listed definition of a threshold event, we report CARs over the interval $[+1,+5]$ of $0.25 \%, 1.56 \%$, and $2.50 \%$ in 2006,2007 , and 2008 , respectively. These results support earlier evidence that suggests that market participants do not view threshold events as negative information but instead view increased naked short selling as a bullish signal because of the latent demand created by short sellers' eventual need to cover their trades. This result is particularly evident in 2008, a year when naked short sellers saw their 
activities constrained by market regulators while many in the media vilified their trades as abusive and manipulative. Overall, the results reported in Table 3 provide little support for the contention that naked short selling exacerbated price declines during the recent financial crisis and instead suggest that the actions of market regulators to constrain the activities of naked short sellers may have been misguided.

\subsection{Cumulative abnormal returns by listing exchange}

In Table 4, we explore the possibility that threshold events differ by listing exchange. Differences may be due to factors such as the characteristics of the firms traded on different exchanges, market structure, and the market maker exemption to naked short sale regulations. We continue to report the results for four threshold event definitions.

\section{<<TABLE 4 ABOUT HERE >>}

In Table 4, we find that the positive CARs in the period before the threshold trades are generally strongest for Nasdaq-listed stocks. CARs over the interval $[-8,-7]$ are consistently statistically significant only for Nasdaq-listed stocks reappearing on the threshold lists after 30-, 90-, and 180-day absences. For example, we report CARs of 3.85\%, 1.58\%, and $0.46 \%$, respectively, for Nasdaq-, AMEX-, and NYSE-listed stocks reappearing on the threshold lists after an absence of at least 30-days. The exception is the sample of stocks making their first appearance on the threshold lists. The average CAR for first-time listings over the interval $[-8,-$ 7] is $3.81 \%$ for stocks trading on the AMEX, $2.36 \%$ for stocks trading on the Nasdaq, and $1.14 \%$ for NYSE-listed firms. 
The CARs reported for the period between the threshold trades and the threshold listing are generally positive regardless of listing exchange. For example, CARs over the interval $[-6,0]$ are $1.26 \%, 1.43 \%$, and $1.21 \%$, respectively, for AMEX-, Nasdaq-, and NYSE-listed stocks making their first appearance on the threshold lists. This confirms earlier evidence that suggests that naked short sellers are typically not able to profitably unwind their position before a stock appears on the threshold lists.

We also report abnormal returns following threshold events by listing exchange. In contrast to the $[-8,-7]$ results, CARs following threshold appearances tend to be larger for NYSE-listings than for firms listed on the AMEX and Nasdaq. For example, we report an average CARs over the period $[+1,+5]$ of $3.29 \%$ for NYSE-listed stocks making their first appearance on the threshold lists. This compares to average CARs of $1.28 \%$ and $0.93 \%$ for AMEX- and Nadaq-listed stocks, respectively. The results are similar for firms reappearing on the threshold lists after an extended absence.

\subsection{Cumulative abnormal returns by threshold absence}

In Table 5, we address the possibility that the information content of threshold events is related to the length of time since a firm last appeared on a threshold list. We divide the events for the 30-, 90-, and 180-day threshold event definitions into quartiles based on the number of days elapsed since a firm previously appeared on a threshold list. Quartile 4 contains the firms reappearing on the threshold lists following the longest absences, while quartile 1 contains the firms reappearing after shorter absences. For example, when threshold events are based on a minimum absence of 30 days, the quartile cutoffs are 251,112, and 57 days, respectively. 


\section{$<<$ TABLE 5 ABOUT HERE $>>$}

Focusing on the 30-day definition for threshold events, we find that CARs in the period before the threshold trades are positively correlated with the length of a firm's absence from the threshold lists. We report CARs of $4.82 \%$ over the interval $[-8,-7]$ for stocks absent from the threshold lists for at least 251 days compared to CARs of $1.25 \%$ over the same period for stocks absent for 51 or fewer days ( $\mathrm{p}$-value of the difference $=0.01$ ). However, this pattern is not evident for the 90- and 180-day subsamples. For these subsamples there is no consistent relation between CARs and a stock's absence from the threshold lists. The remaining event windows provide little evidence of a relation between CARs and the length of time between a stock's appearances on the threshold lists.

\subsection{Cumulative abnormal returns by market capitalization}

D’Avolio (2002) examines the market for borrowing and lending stocks and finds that the shares of larger firms are more readily available for borrowing by short sellers, mainly because institutions, who represent a significant fraction of stock lending, favor large firms. In Table 6, we examine the possibility that the information content of threshold events is related to the market capitalization of stocks appearing on the threshold lists by separating our sample into quartiles based on market value of equity. In Table 1, we reported that the market capitalization of first time threshold listings is noticeably larger than firms reappearing on the threshold lists. The quartile cutoffs for first time listings are \$666 million, \$261 million, and \$106 million, while for firms reappearing after a 30-day absence they are $\$ 395$ million, $\$ 180$ million, and $\$ 78$ million. The cutoffs for firms reappearing after 90 and 180 days are similar to the 30 day cutoffs. 


\section{<<TABLE 6 ABOUT HERE >>}

We find that CARs over the interval $[-8,-7]$ are largest for the quartile containing the smallest firms. For the first time threshold listings, the average CAR for stocks in the largest (smallest) market cap is $-0.47 \%(6.77 \%)$. When we define a threshold event as a reappearance after an absence of at least 30 days, the CARs for the largest and smallest quartiles are $0.91 \%$ and $6.86 \%$, respectively. In contrast to the $[-8,-7]$ results, we find that CARs over the $[-6,0]$ window tend not to be significant for firms in the smallest market capitalization quartile while there is very little difference in returns for the three largest market capitalization quartile. The relation between size and CARs in periods following the announcement that a stock is on the threshold lists is unremarkable.

\subsection{Multivariate analysis of cumulative abnormal returns}

In Table 7, we report the results of ordinary least squares regressions that control for several of factors that might impact CARs around threshold events. The sample includes all first time threshold listings and all repeat threshold listings that follow an absence of at least 30 days. The dependent variable in the regressions is the CAR over several windows before and after the threshold event. To control for the possibility that CARs are related to the length of a stock's absence from the threshold lists, our model includes the natural log of 1 plus the number of days since a firm last appeared on the threshold lists and an indicator variable set to 1 for first time threshold events, and zero otherwise. Ackert and Athanassakos (2005) report a relation between firm size and returns around short sale transactions. Thus, we control for firm size by including 
the natural log of the firm's market capitalization. The inverse of the stock price is included to account for the possibility that naked short sellers trading strategies or that the market's response to information related to naked short selling is related to a firm's stock price. We include controls for the standard deviation of daily returns and turnover (trading volume divided by shares outstanding), measured over the 22 trading days ending the day before the naked short sale transaction(s) that result in a threshold listing (t-8). Finally, indicator variables are set to 1 for firms operating in a high tech industry, Nasdaq-listed stocks, and threshold events that take place during the bear market of 2008, and zero otherwise.

\section{$<<$ TABLE 7 ABOUT HERE〉>}

The first two results columns in Table 7 consider CARs for periods leading up to and including the day of the threshold trades. We find that CARs are larger for firms reappearing on the threshold lists after an extended absence, first time threshold list appearances, higher priced stocks, stocks with more volatile returns, and stocks with lower turnover. Consistent with Table 3, we find that CARs are 3.1-4.2 percentage points lower for events taking place in 2008. This suggests that naked short sellers' tendency to trade stocks experiencing recent positive CARs was diminished during the bear market of 2008. However, as detailed earlier, we find little evidence to suggest that naked short sellers tend to transact following periods of price weakness during any of our sample years.

In the third results column we examine CARs for the period $[-6,0]$, which begins the day after the threshold trades and extends to the day of the threshold appearance. CARs measured over this period tend to be positively related to market capitalization, stock price, and the 
standard deviation of returns and negatively related to turnover. The forth column reports the results for CARs for the period $[+1,+5]$. We find that CARs over this period are generally 2.8 percentage points larger for first time threshold listings and 1.2 percentage points larger for events taking place in 2008 .

\section{Conclusions}

The purpose of this paper is twofold. First, we study naked short sellers' behavior for insight into their trading strategies and their ability to identify overpriced stocks. We find that naked short sellers are contrarians who trade following positive abnormal returns. We find no evidence that naked short sellers are informed traders who profit from subsequent negative abnormal returns. Second, we study the market's reaction to announcements indicating increased levels of naked short selling. We find abnormal returns are generally positive following such announcements.

Our results suggest that the SEC's recent regulatory actions restricting naked short selling may have been misplaced, as we find no evidence that naked short sellers are informed traders who exacerbate downward price momentum or are negatively viewed by the market. Instead, our results complement studies that suggest that naked short sellers promote efficient markets by providing liquidity in up markets, risk-bearing, and selling stocks they view as overpriced. 


\section{References}

Ackert, L.F., Athanassakos G., 2005. The Relationship between Short Interest and Stock Returns in the Canadian Market. Journal of Banking and Finance 29, 1729-1749.

Aitken, M.J., Frino, A., McCorry, M.S., Swan, P.L., 1998. Short Sales are Almost Instantaneously Bad News: Evidence from the Australian Stock Exchange. Journal of Finance 53, 2205-2223.

Angel, J.J., Christophe, S.E., Ferri, M.G., 2003. A Close Look at Short Selling on Nasdaq. Financial Analysts Journal 59, 66-74.

Arnold, T., Butler, A.W., Crack, T.F., Zhang, Y., 2005. The Information Content of Short Interest: A Natural Experiment. Journal of Business 78, 1307-1335.

Asquith, P., Meulbroek, L., 1996. An Empirical Investigation of Short Interest. Working paper, Harvard University.

Asquith, P., Pathak, P.A., Ritter, J.R., 2005. Short Interest, Institutional Ownership, and Stock Returns. Journal of Financial Economics 78, 243-276.

Boehmer, E., Jones, C.M., Zhang, X., 2008. Which Shorts are Informed? Journal of Finance 63, 491-527.

Boehmer, E., Wu, J., 2009. Short Selling and the Informational Efficiency of Prices. Working paper, University of Georgia.

Boni, L., 2006. Strategic Delivery Failures in U.S. Equity Markets. Journal of Financial Markets $9,1-26$.

Boulton, T.J., Braga-Alves, M.V., 2009. The Skinny on the 2008 Naked Short Sale Restrictions. Working paper, Miami University. 
Brown, S.J., Warner, J.B., 1985. Using Daily Stock Returns: The Case of Event Studies. Journal of Financial Economics 14, 3-31.

Christophe, S.E., Ferri, M.G., Angel, J.J., 2007. Should Owners of Nasdaq Stocks Fear ShortSelling? Journal of Portfolio Management 33, 122-131.

D’Avolio, G., 2002. The market for borrowing stock. Journal of Financial Economics 66, 271306.

Desai, H., Ramesh, K., Thiagarajan, S.R., Balachandran, B.V., 2002. An Investigation of the Informational Role of Short Interest in the Nasdaq Market. Journal of Finance 57, 22632287.

Diamond, D.E., Verrecchia, R.E., 1987. Constraints on Short-Selling and Asset Price Adjustments to Private Information. Journal of Financial Economics 18, 277-311.

Diether, K.B., Lee, K.H., Werner, I.M., 2008. Short-Sale Strategies and Return Predictability. Review of Financial Studies 22, 575-607.

Evans, R.B., Geczy, C.C., Musto, D.K., Reed, A.V., 2009. Failure is an Option: Impediments to Short Selling and Options Prices. Review of Financial Studies 22, 1955-1980.

Fotak, V., Raman, V., Yadav, P.K., 2009. Naked Short Selling: The Emperor's New Clothes? Working paper, University of Oklahoma.

Ljungqvist, A., Wilhelm, W.J., 2003. IPO Pricing and the Dot-com Bubble. Journal of Finance $58,723-752$.

Miller, E., 1977. Risk, Uncertainty and Divergence of Opinion. Journal of Finance 32, 11511168.

Senchack, A.J., Starks, L.T., 1993. Short-Sale Restrictions and Market Reactions to ShortInterest Announcements. Journal of Financial and Quantitative Analysis 28, 177-194. 
Figure 1

Timeline of FTDs

This figure identifies the important dates surrounding naked short sales and failures to deliver. The benchmark date ( $\mathrm{t}=0$ ) is the date of a security's initial appearance on the threshold lists. It is important to note that the threshold lists are released after the close of trading on the benchmark date.

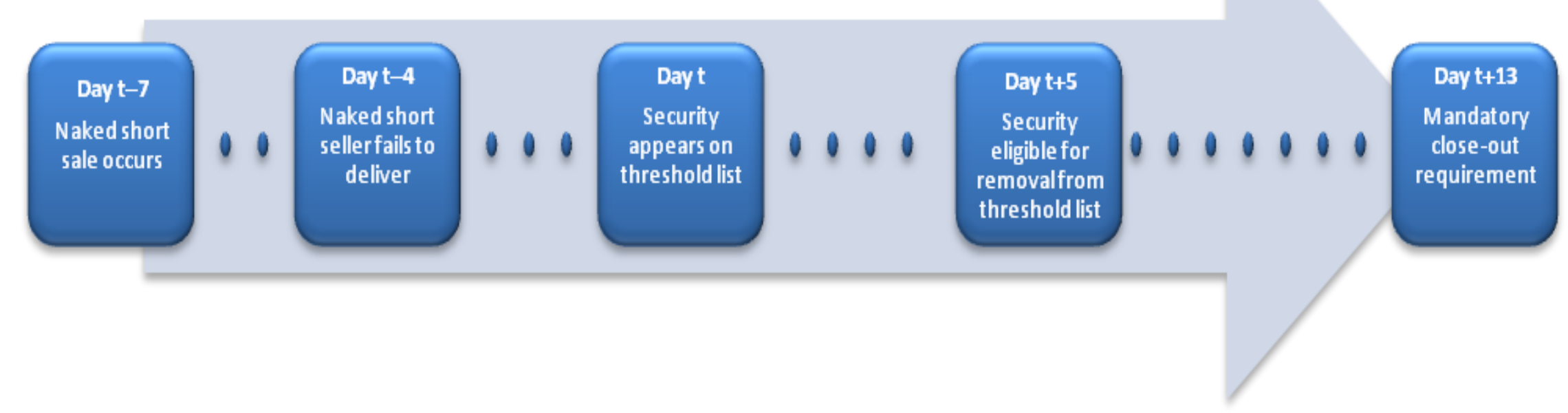


Figure 2

Daily number of threshold securities

This figure details the number of securities appearing on the threshold lists released by the AMEX, Nasdaq, and NYSE on a daily basis over the January 7, 2005 through December 31, 2008 sample period.

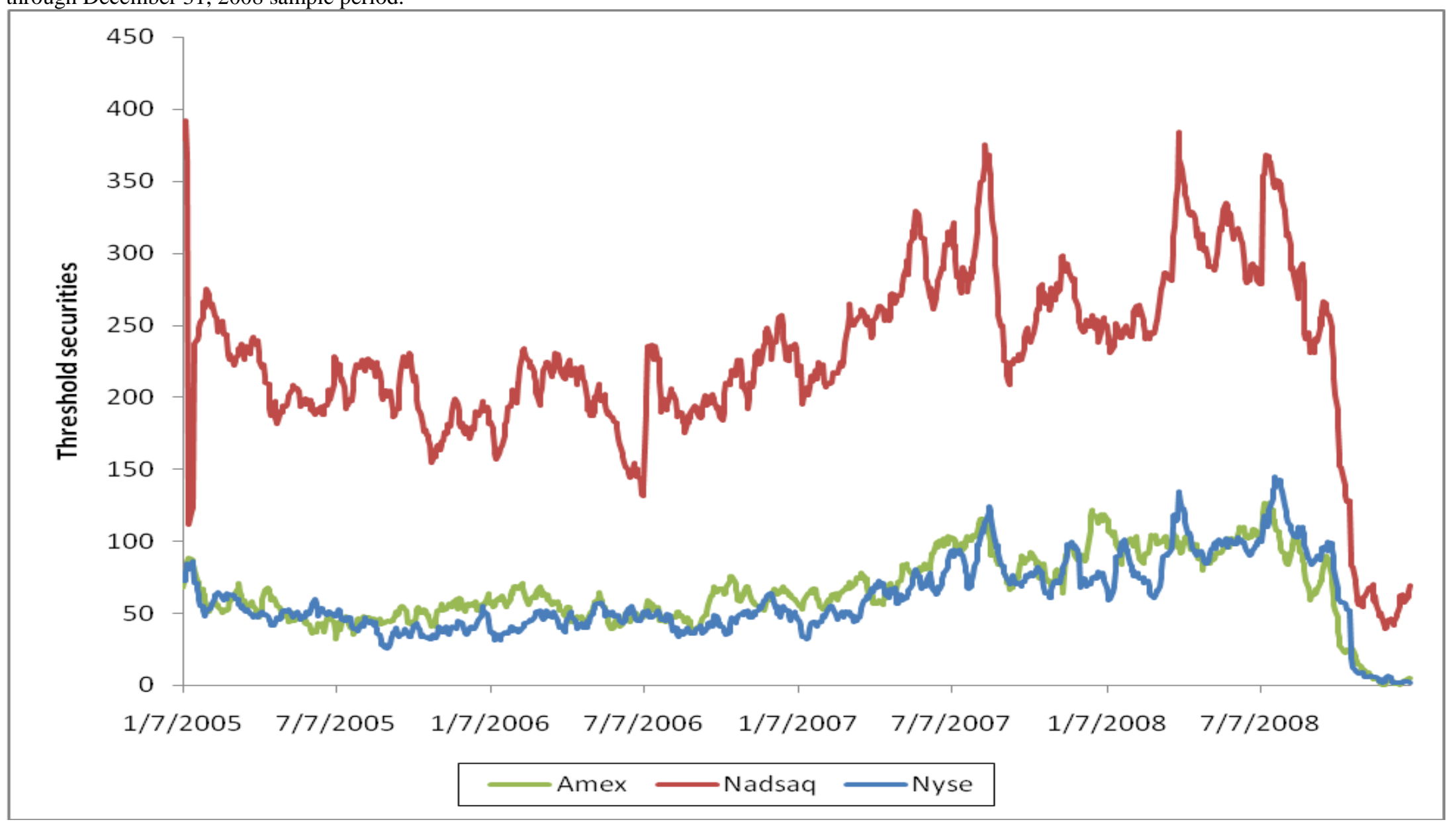


Figure 3

Frequency distribution of threshold events by firm

This figure reports a histogram of the total number of threshold events by firm from 2005 through 2008. Threshold events are defined as (a) a firm's first appearance on the threshold lists and (b) reappearances on the threshold lists following an absence of at least 5 days.

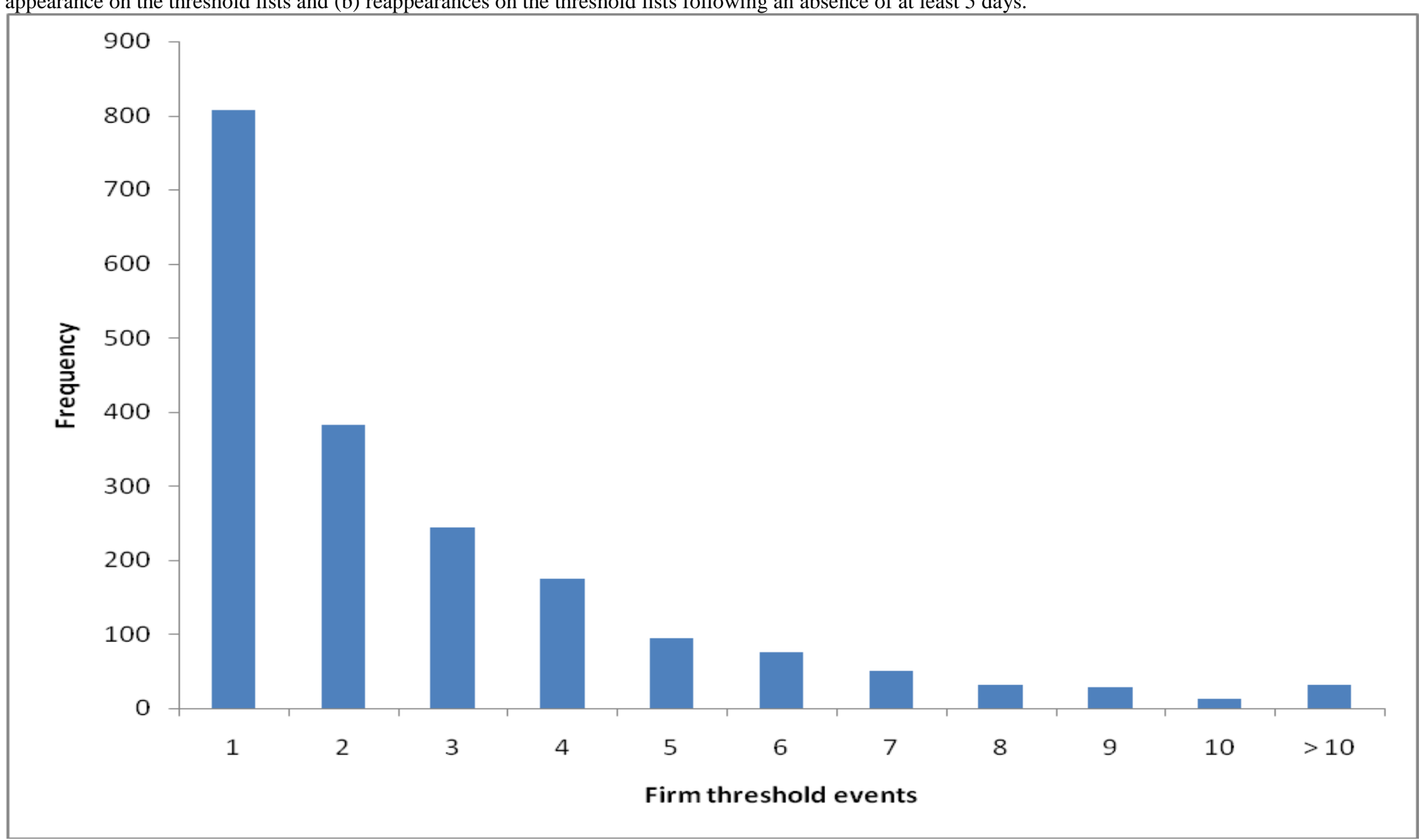


Figure 4

Frequency distribution of threshold list duration

This figure reports a histogram of the duration of threshold events from 2005 through 2008 . Threshold events are defined as (a) a firm's first appearance on the threshold lists and (b) reappearances on the threshold lists following an absence of at least 5 days.

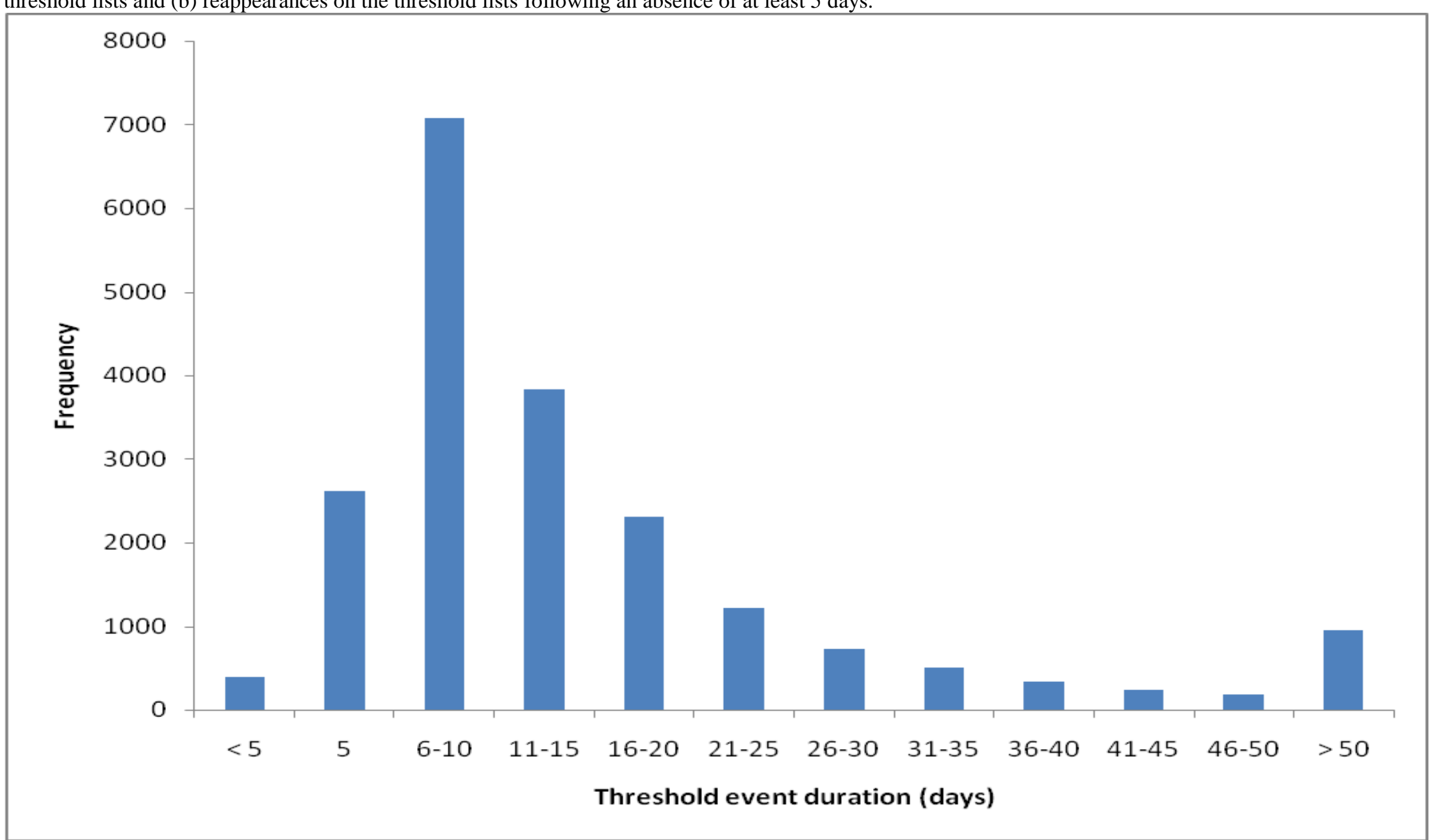


Table 1

Event study sample descriptive statistics

This table reports descriptive statistics for threshold events. Threshold events are defined as (a) first time appearances on the threshold lists and (b) reappearances after absences of at least 30, 90, and 180 days. Absence since last event is the average of the number of days since a firms' prior appearance on the threshold lists. Market capitalization and stock price are measured as of the event date. The standard deviation of returns is the standard deviation of daily returns over the 22 days beginning 8 days before the event. Turnover is the average of the ratio of shares traded to shares outstanding over the 22 days beginning 8 days before the event. High tech is a dummy variable set to 1 for firms with SIC codes identified as high tech industries by Ljungqvist and Wilhelm (2003), and zero otherwise. Nasdaq listed is a dummy variable set to 1 for firms listed on the Nasdaq stock exchange, and zero otherwise. Year 2008 event is a dummy variable set to 1 for events taking place in 2008 , and zero otherwise.

\begin{tabular}{|c|c|c|c|c|}
\hline & $\begin{array}{c}\text { First time } \\
\text { threshold listed }\end{array}$ & $\begin{array}{l}\text { 30-day } \\
\text { absence }\end{array}$ & $\begin{array}{l}\text { 90-day } \\
\text { absence }\end{array}$ & $\begin{array}{l}\text { 180-day } \\
\text { absence }\end{array}$ \\
\hline Absence since last event & & 190.420 & 281.071 & 390.463 \\
\hline Market capitalization & $627,044,116$ & $366,594,214$ & $339,738,258$ & $355,459,264$ \\
\hline Stock price & 15.872 & 11.746 & 11.586 & 11.924 \\
\hline Standard deviation of returns & 0.037 & 0.042 & 0.042 & 0.044 \\
\hline Turnover & 0.015 & 0.013 & 0.013 & 0.013 \\
\hline High tech & 0.105 & 0.122 & 0.120 & 0.113 \\
\hline Nasdaq listed & 0.651 & 0.709 & 0.713 & 0.723 \\
\hline Year 2008 events & 0.343 & 0.369 & 0.342 & 0.381 \\
\hline $\mathrm{N}$ & 955 & 1,743 & 1,003 & 622 \\
\hline
\end{tabular}


Table 2

Threshold event abnormal returns

This table reports abnormal returns around threshold events. Results are reported for threshold events defined as (a) first time appearances on the threshold lists and (b) reappearances after absences of at least 30, 90, and 180 days.

Abnormal returns are calculated using the market model. Panel A reports daily abnormal returns for the period [-12, +13], where day 0 corresponds to a threshold event. Panel B reports CARs over several windows, including the period leading up to threshold trades $([-12,-7]$ and $[-8,-7])$, the period between threshold trades and the threshold event $([-6,0])$, and the period following the public release of threshold information $([+1,+5])$. ***, **, and * denote statistical significance at the $1 \%, 5 \%$, and $10 \%$ level, respectively.

Panel A: Daily abnormal returns

\begin{tabular}{|c|c|c|c|c|}
\hline \multirow[b]{2}{*}{$\begin{array}{c}\text { Event } \\
\text { day }\end{array}$} & \multicolumn{4}{|c|}{ Abnormal return } \\
\hline & $\begin{array}{c}\text { First time } \\
\text { threshold listed }\end{array}$ & $\begin{array}{l}\text { 30-day } \\
\text { absence }\end{array}$ & $\begin{array}{l}\text { 90-day } \\
\text { absence }\end{array}$ & $\begin{array}{l}\text { 180-day } \\
\text { absence }\end{array}$ \\
\hline-12 & -0.0015 & -0.0017 & -0.0004 & -0.0003 \\
\hline-11 & -0.0010 & 0.0003 & 0.0014 & 0.0021 \\
\hline-10 & -0.0015 & 0.0015 & 0.0023 & 0.0001 \\
\hline-9 & -0.0008 & 0.0010 & 0.0014 & 0.0020 \\
\hline-8 & 0.0016 & $0.0083 * * *$ & $0.0118 * * *$ & $0.0132 * *$ \\
\hline-7 & $0.0156^{* *}$ & $0.0220 * * *$ & $0.0292 * * *$ & $0.0434 * * *$ \\
\hline-6 & 0.0007 & $0.0028 *$ & 0.0034 & $0.0052 * *$ \\
\hline-5 & $0.0043 * *$ & 0.0016 & 0.0028 & 0.0022 \\
\hline-4 & $0.0033 * *$ & 0.0010 & 0.0020 & 0.0017 \\
\hline-3 & 0.0010 & $0.0028 * *$ & $0.0048 * * *$ & 0.0022 \\
\hline-2 & -0.0011 & 0.0000 & -0.0011 & 0.0007 \\
\hline-1 & $0.0029 * *$ & $0.0036 * * *$ & 0.0020 & $0.0044 * *$ \\
\hline 0 & 0.0024 & 0.0007 & 0.0004 & -0.0005 \\
\hline 1 & $0.0040 * *$ & $0.0058 * * *$ & $0.0072 * * *$ & $0.0097 * * *$ \\
\hline 2 & $0.0050 * * *$ & $0.0025^{* *}$ & $0.0051 * * *$ & $0.0048 * *$ \\
\hline 3 & 0.0011 & 0.0014 & -0.0000 & -0.0020 \\
\hline 4 & 0.0017 & $0.0028 * *$ & $0.0038 * *$ & 0.0029 \\
\hline 5 & $0.0035^{* *}$ & 0.0004 & 0.0017 & $0.0037^{*}$ \\
\hline 6 & -0.0001 & 0.0007 & 0.0011 & -0.0004 \\
\hline 7 & 0.0000 & 0.0011 & 0.0001 & 0.0002 \\
\hline 8 & 0.0005 & -0.0000 & 0.0003 & 0.0023 \\
\hline 9 & 0.0017 & 0.0008 & 0.0010 & 0.0020 \\
\hline 10 & -0.0004 & 0.0007 & 0.0001 & 0.0004 \\
\hline 11 & -0.0001 & -0.0015 & -0.0015 & 0.0004 \\
\hline 12 & 0.0010 & 0.0002 & 0.0009 & 0.0021 \\
\hline 13 & 0.0005 & 0.0006 & 0.0008 & 0.0010 \\
\hline
\end{tabular}


Panel B: Cumulative abnormal returns

\begin{tabular}{|c|c|c|c|c|c|c|c|}
\hline & $\mathrm{N}$ & {$[-12,-7]$} & {$[-8,-7]$} & {$[-6,0]$} & {$[+1,+5]$} & {$[+6,+13]$} & {$[-6,+13]$} \\
\hline First-time threshold listed & 955 & 0.0125 & $0.0172 * *$ & $0.0136 * * *$ & $0.0152 * * *$ & 0.0031 & $0.0319 * * *$ \\
\hline 30-day absence & 1,743 & $0.0313 * * *$ & $0.0303 * * *$ & $0.0125^{* * *}$ & $0.0129 * * *$ & 0.0025 & $0.0279 * * *$ \\
\hline 90-day absence & 1,003 & $0.0456 * * *$ & $0.0410 * * *$ & $0.0135 * * *$ & $0.0177 * * *$ & 0.0027 & $0.0338 * * *$ \\
\hline 180-day absence & 622 & $0.0602 * * *$ & $0.0566 * * *$ & $0.0161 * * *$ & $0.0191 * * *$ & 0.0080 & $0.0431 * * *$ \\
\hline
\end{tabular}


Table 3

Threshold event cumulative abnormal returns by event year

This table reports abnormal returns around threshold events by year. Results are reported for threshold events defined as (a) first time appearances on the threshold lists and (b) reappearances after absences of at least 30, 90, and 180 days. Abnormal returns are calculated using the market model. CARs are reported over several windows, including the period leading up to threshold trades $([-12,-7]$ and $[-8,-7])$, the period between threshold trades and the threshold event ([$6,0])$, and the period following the public release of threshold information $([+1,+5])$. ***, **, and * denote statistical significance at the $1 \%, 5 \%$, and $10 \%$ level, respectively.

\begin{tabular}{|c|c|c|c|c|c|c|c|c|}
\hline \multirow{4}{*}{ First-time threshold listed } & Year & $\mathrm{N}$ & {$[-12,-7]$} & {$[-8,-7]$} & {$[-6,0]$} & {$[+1,+5]$} & {$[+6,+13]$} & {$[-6,+13]$} \\
\hline & 2006 & 262 & $0.0456 * *$ & $0.0402 * *$ & 0.0083 & 0.0025 & 0.0002 & 0.0110 \\
\hline & 2007 & 365 & $0.0169 *$ & $0.0199 * *$ & 0.0058 & $0.0156 * * *$ & -0.0047 & 0.0167 \\
\hline & 2008 & 328 & $-0.0189 *$ & -0.0042 & $0.0264 * * *$ & $0.0250 * * *$ & $0.0142 *$ & $0.0654 * * *$ \\
\hline \multirow[t]{3}{*}{ 30-day absence } & 2006 & 454 & $0.0523 * * *$ & $0.0478 * * *$ & 0.0053 & 0.0069 & 0.0027 & 0.0149 \\
\hline & 2007 & 645 & $0.0245 * * *$ & $0.0291 * * *$ & $0.0129 * *$ & $0.0108 * *$ & -0.0010 & $0.0227 * * *$ \\
\hline & 2008 & 644 & $0.0234 * *$ & $0.0191 * *$ & $0.0171 * * *$ & $0.0190 * * *$ & 0.0060 & $0.0422 * * *$ \\
\hline \multirow[t]{3}{*}{ 90-day absence } & 2006 & 284 & $0.0700 * * *$ & $0.0622 * * *$ & 0.0099 & $0.0147 * *$ & 0.0008 & $0.0253 *$ \\
\hline & 2007 & 376 & $0.0415 * * *$ & $0.0388 * * *$ & $0.0207 * * *$ & $0.0184 * * *$ & -0.0082 & $0.0309 * * *$ \\
\hline & 2008 & 343 & $0.0301 *$ & $0.0257 *$ & 0.0086 & $0.0194 * * *$ & $0.0163 *$ & $0.0441 * * *$ \\
\hline \multirow[t]{3}{*}{ 180-day absence } & 2006 & 159 & $0.1143 * * *$ & $0.0995 * * *$ & 0.0124 & $0.0178 *$ & 0.0060 & $0.0362 *$ \\
\hline & 2007 & 226 & $0.0456^{* *}$ & $0.0470 * * *$ & $0.0237 * * *$ & $0.0154 *$ & -0.0096 & $0.0294 * *$ \\
\hline & 2008 & 237 & $0.0379 *$ & $0.0369 *$ & 0.0113 & $0.0234 * * *$ & $0.0262 * *$ & $0.0608 * * *$ \\
\hline
\end{tabular}


Table 4

Threshold event cumulative abnormal returns by listing exchange

This table reports abnormal returns around threshold events by listing exchange. Results are reported for threshold events defined as (a) first time appearances on the threshold lists and (b) reappearances after absences of at least 30, 90, and 180 days. Abnormal returns are calculated using the market model. CARs are reported over several windows, including the period leading up to threshold trades $([-12,-7]$ and $[-8,-7])$, the period between threshold trades and the threshold event $([-6,0])$, and the period following the public release of threshold information $([+1,+5]) . * * *, * *$, and $*$ denote statistical significance at the $1 \%, 5 \%$, and $10 \%$ level, respectively.

\begin{tabular}{|c|c|c|c|c|c|c|c|c|}
\hline \multirow{3}{*}{ First-time threshold listed } & Exchange & $\mathrm{N}$ & {$[-12,-7]$} & {$[-8,-7]$} & {$[-6,0]$} & {$[+1,+5]$} & {$[+6,+13]$} & {$[-6,+13]$} \\
\hline & Amex & 111 & $0.0411 * *$ & $0.0381 * * *$ & 0.0126 & 0.0128 & $-0.0269 * *$ & -0.0013 \\
\hline & Nasdaq & 622 & $0.0216 * *$ & $0.0236 * *$ & $0.0143 * *$ & $0.0093 * *$ & 0.0092 & $0.0327 * * *$ \\
\hline \multirow{4}{*}{ 30-day absence } & Nyse & 222 & $-0.0274 * * *$ & $-0.0114 *$ & 0.0121 & $0.0329 * * *$ & 0.0011 & $0.0461 * * *$ \\
\hline & Amex & 259 & $0.0243 *$ & $0.0158 *$ & 0.0040 & 0.0074 & -0.0011 & 0.0103 \\
\hline & Nasdaq & 1,235 & $0.0376 * * *$ & $0.0385 * * *$ & $0.0124 * * *$ & $0.0121 * * *$ & -0.0002 & $0.0243 * * *$ \\
\hline & Nyse & 249 & 0.0073 & 0.0046 & $0.0215^{* * *}$ & $0.0222 * * *$ & $0.0199 * *$ & $0.0636 * * *$ \\
\hline \multirow[t]{3}{*}{ 90-day absence } & Amex & 169 & 0.0261 & 0.0124 & 0.0032 & $0.0207 * *$ & -0.0023 & 0.0215 \\
\hline & Nasdaq & 715 & $0.0564 * * *$ & $0.0544 * * *$ & $0.0167 * * *$ & $0.0148 * * *$ & 0.0036 & $0.0351 * * *$ \\
\hline & Nyse & 119 & 0.0087 & 0.0011 & 0.0086 & $0.0306 * * *$ & 0.0044 & $0.0436 * *$ \\
\hline \multirow[t]{3}{*}{ 180-day absence } & Amex & 104 & $0.0425^{*}$ & 0.0197 & 0.0083 & $0.0257 *$ & 0.0079 & 0.0415 \\
\hline & Nasdaq & 450 & $0.0737 * * *$ & $0.0744 * * *$ & $0.0178 * * *$ & $0.0151 * * *$ & 0.0080 & $0.0409 * * *$ \\
\hline & Nyse & 68 & -0.0016 & -0.0047 & 0.0165 & $0.0355^{* *}$ & 0.0081 & $0.0600 * *$ \\
\hline
\end{tabular}


Table 5

Threshold event abnormal returns by time since threshold last reached

This table reports abnormal returns around threshold events by the time since the last threshold list appearance. Results are reported for threshold events defined as reappearances after absences of at least 30, 90, and 180 days. Firms are separated into quartiles based on the time since the last threshold list appearance.

Quartile 4 (1) corresponds to firms experiencing the longest (shortest) absence from the threshold lists. Abnormal returns are calculated using the market model.

CARs are reported over several windows, including the period leading up to threshold trades $([-12,-7]$ and $[-8,-7])$, the period between threshold trades and the threshold event $([-6,0])$, and the period following the public release of threshold information $([+1,+5])$. ***, $* *$, and $*$ denote statistical significance at the $1 \%$, $5 \%$, and $10 \%$ level, respectively.

\begin{tabular}{|c|c|c|c|c|c|c|c|c|}
\hline & $\begin{array}{l}\text { Absence } \\
\text { quartile }\end{array}$ & $\mathrm{N}$ & {$[-12,-7]$} & {$[-8,-7]$} & {$[-6,0]$} & {$[+1,+5]$} & {$[+6,+13]$} & {$[-6,+13]$} \\
\hline \multirow[t]{4}{*}{ 30-day absence } & 4 & 436 & $0.0499 * * *$ & $0.0482 * * *$ & $0.0156^{* *}$ & $0.0119 * *$ & 0.0086 & $0.0360 * * *$ \\
\hline & 3 & 445 & $0.0477 * * *$ & $0.0402 * * *$ & 0.0092 & $0.0238 * * *$ & -0.0019 & $0.0311 * * *$ \\
\hline & 2 & 428 & $0.0171^{*}$ & $0.0199 * * *$ & 0.0102 & $0.0167 * * *$ & -0.0035 & $0.0234 * *$ \\
\hline & 1 & 434 & 0.0099 & $0.0125^{* *}$ & $0.0150 * *$ & -0.0012 & 0.0069 & $0.0207 *$ \\
\hline \multirow{3}{*}{ 90-day absence } & 3 & 251 & $0.0535^{* *}$ & $0.0516^{* *}$ & $0.0147 *$ & $0.0112 *$ & $0.0157 * *$ & $0.0415^{* * *}$ \\
\hline & 2 & 254 & $0.0661 * * *$ & $0.0573 * * *$ & 0.0071 & $0.0220 * * *$ & -0.0014 & 0.0277 \\
\hline & 1 & 247 & $0.0204 *$ & 0.0147 & $0.0182 * *$ & $0.0228 * * *$ & -0.0096 & $0.0314 * *$ \\
\hline \multirow[t]{3}{*}{ 180-day absence } & 4 & 156 & $0.0378^{*}$ & $0.0327 * *$ & 0.0136 & 0.0055 & 0.0092 & 0.0283 \\
\hline & 3 & 155 & $0.0743 * *$ & $0.0752 * *$ & $0.0160 *$ & $0.0236 * *$ & 0.0069 & $0.0462 * * *$ \\
\hline & 1 & 155 & $0.1100 * * *$ & $0.0994 * * *$ & 0.0190 & $0.0383 * * *$ & 0.0035 & $0.0608 * * *$ \\
\hline
\end{tabular}


Table 6

Threshold event abnormal returns by market capitalization

This table reports abnormal returns around threshold events by market capitalization. Results are reported for threshold events defined as (a) first time appearances on the threshold lists and (b) reappearances after absences of at least 30, 90, and 180 days. Firms are separated into quartiles based on on market value of equity. Quartile 4 (1) corresponds to firms with the largest (smallest) market capitalization. Abnormal returns are calculated using the market model.

CARs are reported over several windows, including the period leading up to threshold trades $([-12,-7]$ and $[-8,-7])$, the period between threshold trades and the threshold event $([-6,0])$, and the period following the public release of threshold information $([+1,+5])$. $* * *, * *$, and $*$ denote statistical significance at the $1 \%$, $5 \%$, and $10 \%$ level, respectively.

\begin{tabular}{|c|c|c|c|c|c|c|c|c|}
\hline & $\begin{array}{l}\text { Price } \\
\text { quartile }\end{array}$ & $\mathrm{N}$ & {$[-12,-7]$} & {$[-8,-7]$} & {$[-6,0]$} & {$[+1,+5]$} & {$[+6,+13]$} & {$[-6,+13]$} \\
\hline \multirow[t]{4}{*}{ First-time threshold listed } & 4 & 239 & -0.0040 & -0.0047 & $0.0192 * * *$ & $0.0113 *$ & -0.0026 & $0.0279 * *$ \\
\hline & 3 & 239 & -0.0029 & 0.0028 & $0.0125 *$ & 0.0081 & -0.0033 & 0.0173 \\
\hline & 2 & 239 & -0.0063 & 0.0032 & 0.0037 & $0.0281 * * *$ & 0.0031 & $0.0348 * *$ \\
\hline & 1 & 238 & $0.0633 * *$ & $0.0677 * * *$ & $0.0189 *$ & 0.0134 & 0.0152 & $0.0475 * * *$ \\
\hline \multirow{3}{*}{ 30-day absence } & 3 & 436 & $0.0153 *$ & $0.0131 *$ & $0.0178 * * *$ & $0.0135 * * *$ & -0.0083 & $0.0230 * *$ \\
\hline & 2 & 436 & $0.0268 * *$ & $0.0305^{* *}$ & $0.0166 * *$ & $0.0168 * * *$ & 0.0029 & $0.0363 * * *$ \\
\hline & 1 & 435 & $0.0631 * * *$ & $0.0686 * * *$ & -0.0045 & $0.0123 *$ & $0.0176^{* *}$ & $0.0254 *$ \\
\hline \multirow[t]{3}{*}{ 90-day absence } & 4 & 251 & $0.0126 *$ & 0.0065 & $0.0146 * *$ & $0.0093 *$ & $-0.0153 * *$ & 0.0086 \\
\hline & 3 & 251 & 0.0134 & 0.0109 & $0.0216 * * *$ & $0.0187 * * *$ & -0.0076 & $0.0327 * *$ \\
\hline & 1 & 250 & $0.1029 * * *$ & $0.0980 * * *$ & -0.0061 & $0.0180 *$ & $0.0289 * *$ & $0.0409 * *$ \\
\hline \multirow[t]{4}{*}{ 180-day absence } & 4 & 156 & 0.0039 & 0.0037 & $0.0166^{* *}$ & $0.0115^{*}$ & -0.0146 & 0.0136 \\
\hline & 3 & 155 & 0.0236 & 0.0240 & $0.0286 * * *$ & $0.0273 * * *$ & -0.0067 & $0.0492 * *$ \\
\hline & 2 & 156 & $0.0724 * *$ & $0.0746 * *$ & $0.0302 * *$ & $0.0212 * *$ & $0.0243 * *$ & $0.0754 * * *$ \\
\hline & 1 & 155 & $0.1412 * * *$ & $0.1244 * * *$ & -0.0112 & 0.0163 & $0.0291 *$ & 0.0343 \\
\hline
\end{tabular}


Table 7

Multivariate analysis of cumulative abnormal returns

This table presents ordinarly least squares regressions of cumulative abnormal returns around threshold events. Threshold events are defined as either a first time appearances on the threshold lists or a reappearance after an absences of at least 30 days. Absence since last event is the natural log of 1 plus the the number of days since a firms last appeared on the threshold lists. First time threshold event is a dummy variable set to 1 for events that represent a firm's first appearance on the threshold lists, and zero otherwise. Market capitalization (natural log) and (inverse) stock price are measured as of the event date. The standard deviation of returns is the standard deviation of daily returns over the 22 days beginning 8 days before the event. Turnover is the average of the ratio of shares traded to shares outstanding over the 22 days beginning 8 days before the event. High tech is a dummy variable set to 1 for firms with SIC codes identified as high tech industries by Ljungqvist and Wilhelm (2003), and zero otherwise. Nasdaq listed is a dummy variable set to 1 for firms listed on the Nasdaq stock exchange, and zero otherwise. Year 2008 event is a dummy variable set to 1 for events taking place in 2008, and zero otherwise.

\begin{tabular}{|c|c|c|c|c|c|c|}
\hline & {$[-12,-7]$} & {$[-8,-7]$} & {$[-6,0]$} & {$[+1,+5]$} & {$[+6,+13]$} & {$[-6,+13]$} \\
\hline Intercept & 0.049 & $0.210^{* *}$ & -0.080 & -0.019 & 0.005 & -0.093 \\
\hline Absence since last event & $0.018 * * *$ & $0.014 * * *$ & 0.001 & 0.005 & 0.001 & 0.007 \\
\hline First time threshold event & $0.072 * *$ & $0.062 * *$ & 0.004 & $0.028 *$ & 0.011 & 0.043 \\
\hline Market capitalization & -0.007 & $-0.014 * * *$ & $0.005^{*}$ & 0.000 & -0.001 & 0.004 \\
\hline Inverse stock price & $-0.149 * * *$ & $-0.122 * * *$ & $-0.044 * * *$ & $0.033 * *$ & $0.036 * *$ & 0.025 \\
\hline Standard deviation of returns & $2.387 * * *$ & $1.704 * * *$ & $0.371 * * *$ & 0.017 & 0.159 & $0.539 * * *$ \\
\hline Turnover & $-1.750 * * *$ & $-1.123 * * *$ & $-0.560 * * *$ & -0.177 & -0.221 & $-0.951 * * *$ \\
\hline High tech & 0.018 & $0.024 *$ & $-0.016^{*}$ & -0.009 & -0.011 & $-0.036 * *$ \\
\hline Nasdaq listed & 0.007 & 0.007 & 0.004 & -0.007 & 0.000 & -0.003 \\
\hline Year 2008 events & $-0.042 * * *$ & $-0.031 * * *$ & 0.006 & $0.012 * *$ & 0.009 & $0.027 * * *$ \\
\hline Adjusted R-square & 0.0728 & 0.0594 & 0.0091 & 0.0060 & 0.0040 & 0.0105 \\
\hline Number of observations & 2,698 & 2,698 & 2,698 & 2,697 & 2,688 & 2,698 \\
\hline
\end{tabular}

